\title{
Quanto você vale? Sociedade para a avaliação dos humanos
}

\section{What Are You Worth? Society for the Evaluation of Humans}

Igor Antic

Andreu Solé2

Traduzido por Rosimeri Carvalho da Silva

\section{Resumo}

Este texto é parte integrante de uma instalação de arte contemporânea concebida e realizada por lgor Antic (artista, Paris) e Andreu Sole (sociólogo, HEC-Paris). A exposição foi apresentada em 2004 na 11ª Bienal de Artes Visuais de Pancevo (Serbia) e em 2005 na exposição "Valores", em Perigueux (França).

Palavras-chave : Sociedade; homens; humanismo

\section{Abstract}

This text is part of an installation of contemporary art by lgor Antic (artist, Paris) and Andreu Solé (sociologist, HEC-Paris). The exhibition took place in 2004 at the $11^{\text {st }}$ Bienal of Visual Arts in Pancevo (Sérvia) and in the year of 2005 at the exhibition "Values", in Perigueux (France).

Key-words : Society; humans; humanism

A vida humana tem um valor - quantificável, faturável, assegurável, negociável, imposto? O valor de um humano pode aumentar ou diminuir?

Informamos a criação de uma sociedade encarregada de coletar e arquivar casos de valorização e desvalorização dos humanos. Envie-nos seu testemunho. Os casos de pessoas que você conhece, das quais ouviu falar são igualmente do nosso interesse. Você pode se identificar ou permanecer anônimo.

Os dossiês (contendo imagens, textos, vídeos ou outros tipos de documentos) podem ser enviados por e-mail para: igorantic@yahoo.com.

\footnotetext{
1 Artista. E-mail: igorantic@yahoo.fr.

2 Doutor em Sociologia. Professor da HEC-Paris. Endereço: 1, Rue de la Libération 78350 - Jouy-en-Josas - France. E-mail: sole@ @hec.fr.

${ }^{3}$ Doutora em Administração pela École de Hautes Études Commerciales - HEC-França. Professora Adjunta do Departamento de Ciências da Administração e do Mestrado em Administração da UFSC. Endereço: CSE - CAD Campus Trindade - Florianópolis - SC - Brasil CEP: 88040900. E-mail: rosimeri@ cse.ufsc.br. 


\section{Quanto você vale?}

Você diz que essa questão é uma provocação a qual não responderá. Está convencido - para se tranqüilizar? que, como adora repetir para si mesmo, a vida de um humano não tem preço. Permita-me, simplesmente, submeter-lhe uma série de acontecimentos - extraordinários e ordinários.

\section{Caso n- 1}

Hoje, no Brasil, pode acontecer de alguns proprietários de terra fecharem contratos com camponeses sem-terra que ocupam ilegalmente pequenas áreas de seus imensos domínios. Freqüentemente, o valor de um contrato é derrisório; algumas dezenas de euros por cabeça. (caso relatado por diversos jornais brasileiros)

\section{Caso n- 2}

Um certo Tudor, 50 anos, desempregado, proveniente de um vilarejo situado a cerca de $50 \mathrm{~km}$ a oeste de Bucareste, na Romênia, vendeu três de seus 11 filhos por 1 milhão de LEVs (24 euros), cada um. Segundo sua confissão, "os mediadores desse negócio foram a secretária do prefeito e dois homens que falavam uma língua estrangeira". As fileiras do tráfico de crianças romenas, destinadas a casais ou proxenetas no Ocidente, parecem passar pela cidade de Pancevo, onde acontece a 11ª Bienal de Artes Visuais. (AGÊNCIA TANJUG)

Talvez, você diga para si mesmo que se trata de um acontecimento relativo a um país "em desenvolvimento", como se diz hoje em dia nos países "desenvolvidos"...

\section{Caso n- 3}

Graças ao seu procedimento de "plastificação" desenvolvido em 1977 e devidamente patenteado, Gunther Von Hagens inventou o cadáver esculturável. Para isso, é necessário banhar o corpo com acetona, para retirar-lhe a água e a gordura, e depois enchê-lo de silicone ou de resina epóxi. Uma vez tornadas maleáveis, essas bonecas sem vida podem ter a pele arrancada e serem moldadas, antes de serem secas numa bolha de gás. [...] Desde a primeira exposição, intitulada "Döperwelten" ("Os mundos dos corpos"), em Mannheim em 1988, cerca de 14 milhões de pessoas, na Alemanha, Coréia e Japão já foram à exibição desses 200 "verdadeiros" corpos plastificados com ares de dilacerados. ${ }^{4}$ No hit parade desse show macabro, o jogador de xadrez deixando aparecer seu sistema nervoso, do canal raquidiano até o cérebro; uma nadadora dividida em duas, ou ainda um ciclista cuja ossatura e músculos foram aumentados duas vezes e meia na escala humana para melhor aproveitar o espetáculo de suas entranhas. [...] Mesmo que sempre quisesse utilizar corpos de doadores, Gunther Von Hagens deu sinal verde no dia 23 de fevereiro de 2002, segundo o semanário Der Spiegel, para a compra de "50 a 60 adultos". O que ele não nega, denunciando de passagem "a hipocrisia daqueles que não querem admitir que há um mercado da morte que escapa a toda a lei". [...] Der Spiegel acusou em janeiro o "Doutor Morte" de estar à frente de um florescente comércio de cadáveres e de ter comprado corpos de condenados à morte chineses. [...] Nesse fim de semana, Der Spiegel evocou a importação fraudulenta de cadáveres russos. O que já se comentava é que Gunther Von Hagens tinha prometido ao antigo jogador de basquete russo Alexander Sizon (2,48 m), acometido de uma doença grave, uma renda vitalícia em troca de seu corpo. (LIBÉRATION, 1.3.2004)

\section{Caso no -4}

Um prisioneiro iraquiano foi espancado até a morte por soldados britânicos, em setembro, em Bassora, e sete outras pessoas, detidas ao mesmo tempo, foram igualmente vítimas de torturas durante três dias, segundo uma detalhada pesquisa publicada no domingo 4 de janeiro pelo semanário britânico The Independent on Sunday. O jornal detalha que segundo o laudo médico liberado pelo exército britânico, a vítima, Baha Mousa, morreu por

\footnotetext{
${ }^{4} \mathrm{O}$ autor utiliza écorché, que no dicionário de francês/português da Porto Editora é traduzido por "dilacerado" como adjetivo, mas que como substantivo tem o sentido de "sem pele": "estátua de homem ou animal sem pele, utilizados pelos estudantes de belas-artes".
} 
"asfixia" quando de sua detenção. [...] "Nada permite sugerir que uma investigação não esteja em curso sobre esse caso", informou ao semanário, sábado, o Ministério da Defesa britânico. Sempre de acordo com o jornal dominical, as autoridades militares britânicas no Iraque, em Bassora, ofereceram US\$8.000 (aproximadamente 6.500 euros) à família de Baha Mousa, como "pagamento definitivo por esse "incidente", observando que o Exército não assumia a responsabilidade pela morte.” (LE MONDE, 5.1.2004)

Talvez, você diga para si mesmo que o comportamento dos militares britânicos é mais inadmissível, uma vez que se trata do Exército de um país "democrático", mas que este foi confrontado com uma situação excepcional...

\section{Caso n ${ }^{-} 5$}

Uma vida é uma vida, nem mais nem menos. A equação é a mesma quando se trata de cadáveres da guerra. As 300.000 mortes provocadas pelos enfrentamentos étnicos no Burundi, que duram 10 anos, deveriam valer tanto quanto a morte de um soldado americano no Iraque, mesmo que os interesses econômicos e geopolíticos sejam diferentes. É o que pensa um grupo de jornalistas do jornal espanhol El Mundo que realizou um documentário na Internet intitulado Guerras esquecidas, conflitos relegados a segundo plano. (artigo do CLARIN.COM, 29.2.2004)

Então, as vidas humanas não são equivalentes. Você sabia disso, não? Você sabia que há prova de que a relação pode ser superior a $1 / 300.000$ ?

\section{Caso $n^{0}-6$}

Você sabia que num país como a França um casal registrou queixa contra seu filho, a fim de recuperar tudo o que ele tinha lhes custado? Desde seu nascimento, eles tinham um caderno para registrar, dia após dia, o que ele lhes custava em alimentação, vestimentas, brinquedos, transporte, lazer...

Você pode dizer para si mesmo que esses pais não são pais - que não se trata de uma mãe, que não se trata de um pai.

\section{Caso $n^{0} \mathbf{7}$}

O senhor Bonjaku, da cidade de Drac, na Albânia, está preso porque vendeu seu filho de três anos para um comprador italiano. Fatmira, a mãe, disse que ele tinha planejado vender também o recém-nascido e que ela também participara da venda de seu filho Oracie, porque pensava que o comprador italiano lhe asseguraria uma vida confortável. Por essa venda, os pais ganharam um televisor, enquanto dois intermediários do negócio ganharam US\$6.000 cada um. (informação publicada em 20.11.2003 pelas agências TANJUG e AVP; comunicada a Igor Antic por Stanisa Dautovic, artista e engenheira)

Um televisor italiano será exposto na 11a Bienal de Artes Visuais em Pancevo.

\section{Caso $n^{0} 8$}

Eu conheço uma dezena de pessoas verdadeiramente talentosas que, de tanto ganhar mal a vida inteira, imigraram para o estrangeiro. Dir-se-ia que lá, elas valem muito mais que aqui. Por exemplo, meu irmão Marko vale 10 vezes mais em Frankfurt do que em Belgrado. Na época, todo mundo considerava que essa "exportação forçada de talentos" era um verdadeiro desperdício para o país. Alguns desses "talentos" retornam freqüentemente à Servia para organizar um tráfico ilegal. É possível vê-los em caminhões, ônibus ou em carros particulares, com suas valises carregadas de antigüidades e de bens culturais protegidos - ícones, móveis, quadros, objetos da pré-história etc. Esses objetos saem do país em direção à Europa Ocidental. Para determinar o valor de um 
objeto de arte, é necessário, primeiro, poder reconhecê-lo, e em seguida saber avaliá-lo. ${ }^{5}$ Nem todos podem fazê-lo. É preciso ter um bom conhecimento da matéria. Entre os que fazem tráfico ilegal, há artistas. Marko é um deles. Em Belgrado, não ganhava nada; em Frankfurt, ele enriquece. Ele viu seu preço aumentar. Ele se garantiu para o resto da vida. Um ícone do século XVII, no seu meio histórico tem um valor inestimável. No estrangeiro pode ultrapassar 12.000 euros, mas isso é uma depreciação. (caso citado por M.C., humano desempregado)

É incrível até que ponto a geografia pode afetar o valor dos humanos sobre a Terra, você não acha? Para que país você foi, ou você sonha ir para aumentar seu valor?

\section{Caso nํㅗ 9}

Você sabe da existência das companhias de seguros. Sabe que pode fazer um seguro de vida com elas. Sabe que em função do quanto você tenha pago e das cláusulas do contrato que tenha firmado, a sua morte, os beneficiários (sua esposa, seu marido, seus filhos...) ganharão dinheiro. Você entendeu que é você que escolhe o seu valor?

Você fez um seguro de vida para você, sua esposa, seus filhos? Em quanto você fixou seu valor, e o da sua esposa e o dos seus filhos?

\section{Caso n- 10}

Você sabia que os esportistas fazem seguro de suas pernas, de seus joelhos, de seus pulsos? Você sabia, por exemplo, que o Real Madrid se garantiu contra a morte ou invalidez de Zidane pela soma de 240.000 euros por ano? (valor citado na Internet)

Os joelhos de Zizou valem, então, 240.000 euros. Quanto valem os seus?

\section{Caso n- 11}

Você sabia que os pianistas colocam seus dedos no seguro, que as cantoras e os cantores de rock fazem seguro de suas vozes e que as vedetes do cinema fazem seguro de seus corpos? Você sabia, por exemplo, que a voz de Bruce Springsteen está segurada em 6 milhões de euros e o corpo de Jennifer Lopez, em 150 milhões de euros? (valor citado na Internet)

Quanto valem seus dedos, sua voz e seu corpo?

\section{Caso $n^{0} 12$}

O acordo de indenização de famílias vítimas do atentado do DC-10 de UTA, assinado sexta-feira em Paris com os libaneses, eliminou o último obstáculo para a normalização das relações entre Paris e Trípoli, 14 anos depois do atentado conta o avião francês atribuído à Líbia. [...] O acordo sobre o pagamento, em quatro vezes, de US \$1 milhão para cada vítima foi assinado sexta pela manhã em Paris entre os representantes das famílias e a fundação beneficente libanesa Kadhafi. No total, a Líbia se comprometeu a pagar US\$170 milhões por esse atentado perpetrado em setembro de 1989 e que resultou em 170 mortos de 17 nacionalidades, 54 dos quais franceses, quando o aparelho foi destruído no deserto do Ténéré (Niger). [...] o acordo entre as famílias das vítimas do vôo UT772 e a Fundação Kadhafi é bem menos vantajoso do que aquele concluído em agosto último entre Washington, Trípoli e Londres para o pagamento de cerca de US $\$ 2,7$ bilhões às famílias das vítimas do atentado de Lockerbie (270 mortos em dezembro de 1988); ou seja, US\$10 milhões para cada família. (Agência FRANCE PRESSE-AFP: 9.1.2004)

\footnotetext{
${ }^{5} \mathrm{O}$ autor utiliza expertise que tem o sentido de "dar parecer, vistoriar, avaliar" por um especialista.
} 
Você acha igualmente insuportável que vidas sejam negociadas por 10 vezes mais que outras? O que é inaceitável para você? A diferença de valor das vidas ou o fato de se quantificar a vida de um humano?

\section{Caso n- 13}

Nos países "desenvolvidos", casais adotam crianças de países "em desenvolvimento" (China, Guatemala...). Para isso, devem desembolsar uma soma significativa (viagem, custo do processo, indenização...). É claro, que pelo bebê (menino ou menina) que trazem no avião, eles não pagaram, não verdadeiramente, já que tudo é legal...

Boa ação ou compra? O que você acha?

\section{Caso n- 14}

O que eu sou aos olhos da maioria - uma nulidade, um homem excêntrico ou desagradável - alguém que não tem lugar na sociedade ou que não vai ter, enfim, um pouco menos que nada. [...] Ainda que eu esteja freqüentemente na miséria, há, no entanto, em mim uma harmonia e uma música calma e pura. No mais pobre casebre, no mais sórdido canto, eu vejo quadros ou desenhos. E meu espírito vai nessa direção levado por uma força irresistível [...]. Eu não posso fazer nada se meus quadros não vendem. Um dia virá, entretanto, quando se verá que isso vale mais que o preço da cor e da minha vida, em suma, muito magra... (carta de Vincent Van Gogh a seu irmão Théo)

Valemos aquilo que nossas obras valem? Qual é a sua obra? Talvez você saiba que Van Gogh só vendeu um quadro na vida (Vigne rouge) - por um valor ridículo. Hoje em dia, suas obras atingem valores absurdos nos leilões. Nós valemos o que valem nossas obras um dia após nossa morte?

\section{Caso n-15}

$\mathrm{Na}$ época em que comecei minha carreira, um colecionador comprou uma dezena das minhas obras. Quando lhe perguntei por que fazia isso, ele me respondeu que estava investindo num jovem artista de valor garantido. Soube recentemente que algumas das minhas obras, mais precisamente algumas daquelas compradas pelo mencionado colecionador, foram revendidas durante a guerra na Iugoslávia, com uma perda aproximada de $60 \%$ do seu valor inicial. Quanto a mim, tenho boa saúde e hoje ganho aproximadamente $75 \%$ mais do que ganhava no início da minha carreira. (Igor Antic, artista)

Investir nas pessoas, não é o que faz - naturalmente - toda empresa?

\section{Caso n- 16}

Quando, há cinco anos, decidi sair da Argentina para vir fazer doutorado na França, tive que enfrentar uma questão recorrente da parte das pessoas próximas a mim: porque deixar teu país para ir para outro que você não conhece, onde não tem amigos; voltar à condição de estudante, agora que é um profissional; se transformar num "estrangeiro" e, além do mais, ganhar três vezes menos? Na época, eu tinha três argumentos, mais ou menos sustentáveis, dependendo do interlocutor: 1) para me valorizar como pessoa, cultivar meu espírito, me abrir para o mundo; 2) é um investimento e, voltando de um país "desenvolvido", eu me venderei bem melhor no mercado de trabalho argentino; e, último argumento, 3) eu sou masoquista. Com o tempo, essa questão tornouse minha e eu continuo tentando respondê-la. Esse mundo "desenvolvido" não se interessa nem um pouco por mim, meu retorno para a Argentina e minhas possibilidades de trabalho lá não são muito encorajadoras e, com a idade, eu descobri que não sou verdadeiramente masoquista. Resta que, hoje, na França, eu valho três vezes menos que, na época, na Argentina: é minha bolsa que se encarrega de me lembrar, cada início de mês. (Pablo Sobrero, pesquisador)

Investir em si mesmo? 


\section{Caso no 17}

Nova York. A grande maioria das vítimas dos atentados do 11 setembro entrou com um pedido de indenização, apesar do sofrimento e das críticas contra o fundo especial criado pelo governo americano. Na segunda-feira, à meia-noite, hora limite para entrega dos dossiês, 2.833 famílias de desaparecidos já tinham dado entrada nos seus pedidos (mais de 95\% delas), assim como 3.624 feridos. Será preciso ainda esperar alguns dias para saber os resultados definitivos, mas isso não deverá fazer diferença. [...] O fato de o fundo exigir que se abra mão de reclamações contra as organizações implicadas no drama (companhias aéreas, as sociedades juridicamente responsáveis pelos imóveis atingidos pelos atentados (as duas torres gêmeas, por exemplo) ou pela segurança portuária) foi um dos principais motivos de hesitação das famílias. Esse fundo foi criado pelo Congresso, duas semanas após os atentados, para impedir que as ações levassem esses setores à falência. [...] O fundo, que já distribuiu um total de US\$1,6 bilhão a 1.160 pessoas (feridos e vítimas), espera que daqui até junho de 2004 todos os dossiês tenham sido estudados e as vítimas, ressarcidas. Até agora, estas receberam em média US\$1,78 milhão (de US\$250.000 a US\$6,9 milhões para os parentes de cada desaparecido; de US\$500 a US\$7,9 milhões para os feridos). (comunicado da agência FRANCE PRESSE - AFP, 24.12.2003)

les sociétés juridiquement responsables des immeubles touchés par les attentats (les 2 tours jumelles de New York, par exemple)".

Você sabe de onde vêm as enormes diferenças nas quantias das indenizações das vítimas dos atentados do 11 de setembro? O governo americano decidiu calcular as somas e pagar de acordo com o salário da vítima. Para você, nesses cálculos, quantas vezes um analista financeiro, um trader, vale uma faxineira porto-riquenha?

Você também acha isso inadmissível? O que exatamente você acha insuportável? Seja sincero consigo mesmo. Nunca, em momento algum, você valeu - aos seus próprios olhos - para melhor e para pior, a quantia do seu salário?

\section{Caso no 18}

Meu pai começou a trabalhar cedo para o pai dele, meu avô. Com nove anos, ele cuidava das vacas. Depois do seu casamento, sem nada, sem dinheiro algum, ele vivia com minha mãe na casa que meus avós tinham num vilarejo da Catalunha (Espanha). Cristobal e ele se ocupavam de vários lotes de terra: parreiras, castanheiras, oliveiras, carobas... Cristobal, um andaluz, logo um "imigrante do interior" na Catalunha, era assalariado. Meu pai trabalhava tão duro quanto ele, mas não recebia salário. Para minha mãe, por exemplo, comprar um par de sapatos, ele tinha de pedir o dinheiro. Aquela situação era cada vez mais insuportável para meu pai. Determinado, ele um dia pediu ao pai para lhe pagar um salário pelo seu trabalho explicando que pagaria um aluguel pela casa. A reação de meu avô foi clara e definitiva: "Nunca, isso vai acontecer entre nós!" Meu pai decidiu partir com a família (minha mãe, meu irmão mais novo e eu) - para o mais longe possível. Há muitos anos, no início de setembro, o trem nos deixou num vilarejo francês com nome alemão, na fronteira com a Alemanha. Eu tinha seis anos. Dias depois de nossa chegada, meu pai começou a trabalhar na construção civil. Algumas semanas depois, ele recebeu seu primeiro salário. Um minguado pagamento. Para meu pai, não receber dinheiro como contrapartida pelo seu trabalho não era viver. Naquele dia, com o modesto pagamento no bolso, ele era - aos seus próprios olhos - um outro homem (testemunho de Andreu Solè, pesquisador).

Você também passou a valer mais aos seus olhos no dia em que recebeu seu primeiro salário?

\section{Caso no 19}

Você sabe, não é mesmo, que a partir de certa idade - cada vez mais cedo - te fazem saber, talvez compreender, que você vale menos, quase nada, talvez nada? Alguns chamam essa desvalorização de "mercado de trabalho". Você sabe disso, não?

A tua idade, hoje, aumenta ou diminui o teu valor? 


\section{Caso n- 20}

Hoje, as empresas oferecem bônus aos executivos, aos operários que aceitam ir trabalhar em países "de risco" (países ameaçados pelo terrorismo, países envolvidos em conflitos étnicos...).

Qual deveria ser o montante desse bônus para que você tivesse vontade de ir trabalhar nesses países?

\section{Caso n- 21}

Um homem, uma voz; é o que se costuma dizer. É o princípio da "democracia”. E sem "democracia”, não há desenvolvimento, é o que se diz. Quando você fala, a sua voz vale tanto quanto a daqueles para os quais se voltam as câmeras, aos quais são estendidos os microfones?

A tua voz vale, 100, 1.000, 10.000, 100.000, 1 milhão de vezes menos?

Você pode ver perfeitamente que a questão que se impõe é "quanto você vale?". Eu me valorizo, você se valoriza; você é valorizado, eu sou valorizado; eu sou desvalorizado, você é desvalorizado (pelos outros, por você mesmo); eu sou revalorizado, você é revalorizado... Quais são os acontecimentos que aumentaram teu valor aos teus olhos, para os outros, quais são aqueles que o diminuíram?

Aceitar essa questão é estar pronto para indagar: isso é normal, está bem, é belo?

\section{Caso n- 22}

Você sabia que em 1989 o governo francês tinha proposto aos hemofílicos com Aids, contraída em transfusões de sangue contaminado, 100.000 francos em troca da renúncia a processos judiciais? Você sabia que uma associação conseguiu impedir esse processo? "Não se compra a morte das pessoas", explicou, em 1991, num debate na televisão, um dos responsáveis por essa associação.

\section{Caso $n^{-} \mathbf{2 3}$}

"Fernando ha vuelto" (Fernando voltou). Fernando é o filho, o irmão, o bem-amado. Em 1973, como milhares de outros jovens chilenos, Fernando foi preso, torturado, assassinado. Sua família nunca mais o viu. Ela esperou 25 anos para ter notícias suas, aquelas que lhe foram transmitidas pelo Instituto Médico Legal do Chile: uma mensagem em forma de ossos (...) Fernando ha vuelto é um documentário que Silvio Caiozzi realizou em 1998. Foi exibido no dia 12 de setembro de 2003 na Cinemateca de Montreal, no dia seguinte ao trigésimo aniversário do golpe de Estado de Pinochet. [...] Para se dedicar às atividades da associação, Patricia Silva Soto (presidente da Associação das Famílias de Pessoas Assassinadas sob a Ditadura - Agrupacion de Familiares de Ejecutados Políticos, Afep) abandonou seu trabalho de parteira. Ela estava de passagem por Montreal no dia 17 de setembro de 2004 [...] "Não há reconciliação possível no Chile. A reconciliação é uma aproximação entre duas partes que estavam conciliadas numa época; esse não é o caso no Chile", disse Patrícia. Ela recusa também a idéia da indenização das vítimas ser calculada sobre o que a pessoa desaparecida ganhava, a fim de obter uma reparação igual para todos. "O valor da cada pessoa é o mesmo. Nós queremos um reconhecimento moral", clama ela. ("Chili: la douleur derrière la façade", crônica de Brigitte Verdière. Disponível em: <www. cybersolidaires.org/actus/chili.html>)

\section{Caso n- 24}

Finalmente, você sabia que cerca de 60 famílias vítimas dos atentados do 11 de setembro desistiram de pedir indenizações, preferindo recorrer aos tribunais para ter uma resposta quanto às responsabilidades, faltas e erros que, segundo elas, contribuíram para a catástrofe? (comunicado da agência FRANCE PRESSE - AFP, 24.12.2003) 
O que você pensa daqueles que, aqui e lá, recusam o dinheiro que lhes é oferecido por uma vida perdida ou destruída - e para que se calem? Imbecis, malandros, perversos, humanos dignos...? 